\title{
Relationships Between Interior and Exterior Spaces as a Factor of Efficient University Buildings
}

\author{
Oday Qusay Abdulqader ${ }^{*}$, Joan Atheel Ahmed ${ }^{2}$ \\ ${ }^{1}$ Department of Architectural Engineering, College of Engineering, University of Mosul, Mosul 41002, Iraq \\ ${ }^{2}$ Department of Computer Engineering, Collage of Engineering, University of Mosul, Mosul 41002, Iraq
}

Corresponding Author Email: odaychalabi@uomosul.edu.iq

https://doi.org/10.18280/ijdne.150518

Received: 29 July 2020

Accepted: 20 September 2020

\section{Keywords:}

interior design, university buildings, educational buildings comfortable space, green design, users' needs

\begin{abstract}
Universities are focusing on the students' needs as a part of interior space elements in the designing processes. However, these needs related to the design of the environmental and formulating systems. Students prefer a comfortable interior space for movement and social activities. Therefore, comfortability should be considered in the design process of the educational building, especially for students' space. The study observed the negative space in the buildings of the University of Mosul, which students lost the healthy relationship between the open and interior space in Students' space. The gathering points inside and outside buildings is the focus of the current study. Therefore, the problem statement is "There is a gap in the design processes of the interior space that provides a comfortable students' space". Therefore, the main research question is "What are influencing factors of the designing and adaptive reuse processes of the interior space in the university buildings". The research aim is "to identify the important factors that influence students' needs in the educational building at the University of Mosul". A quantitative approach applied by using questioner and measuring instruments to collect data from selected case in the University of Mosul. The triangulation of the data shows the importance of direct connection between the exterior and interior space. Besides, the availability of green area, green elements, and comfortable area in the exterior and interior space are the important factors as results showed. Partially, the majority (81\%) of the students preferred a free space that can students adapted to space.
\end{abstract}

\section{INTRODUCTION}

The influencing factors on architecture and interior design processes are the tools for generating efficient spaces, which can be matched with uses needs in educational buildings. The designers should combine interior with open space to reach the efficiency of interior design and achieve students' needs. The integration between interior space and architectural characteristics can propose a place where physiological and psychological needs can be reached. Presently, designing universities buildings considered the student' area as a part of the design. Therefore, the environmental and formulating system are the factors of creating successful space. The users' behaviour is a reaction to the characteristics of interior design, which related to the physical and psychical factors of interior space. Various factors can influence the behaviour of the users, which architects and interior designers must be considered in the design processes, such as, open spaces feature, safety, aesthetic, and health concerns [1]. Therefore, comfortable and formulate systems are the generator of how users behave in the space. As usual, students prefer a comfortable space that can use for movement, academics, and social activity. Therefore, the availability of comfortable space in the essential point that should be considered in the design process.

The current study observed the spaces in the selected building at the University of Mosul. The students' need a special space within the building to feel like part of the place. 'belonging to the place' factor should be activated, which attracts the students to be part of the interior space. The buildings in the University of Mosul- College of Engineering are mostly adapted to be re-used, such as, Architectural Engineering Department building which is originally designed for Electric Engineering Department. Then, Central Library, which the interior space needs for the function are different from function to another. Therefore, the problem statement of the current paper "There is a gap in the design processes of the interior space that provides a comfortable students' space". Therefore, the research question "What are influencing factors of the designing and adaptive reuse processes of the interior space in the university buildings". The study aims to identify the essential factors that influence students' needs in the interior space. The efficiency of the space depends on the various factors that affected the physical and psychological needs of the students. To reach the aim of the study, the first step is to review the literature that linked the interior design aspects of users' behaviour. Moreover, environmental studies reviewed to identify the requirements of the comfortable area in the academic buildings to create a theoretical framework of the study.

\section{LITERATURE REVIEW}

Groter [2] mentioned the importance of the relationships between outdoor and indoor, which should include integrational relations. The continuity between the exterior 
and interior design have a role in creating such an aesthetic and attractive place. Reaching the psychological, physical, and emotional needs are the results of the perfect relationships between the surrounding and buildings as More's study [3], which influence the users to adapt, attached, and sense the place (Figure 1) [3].

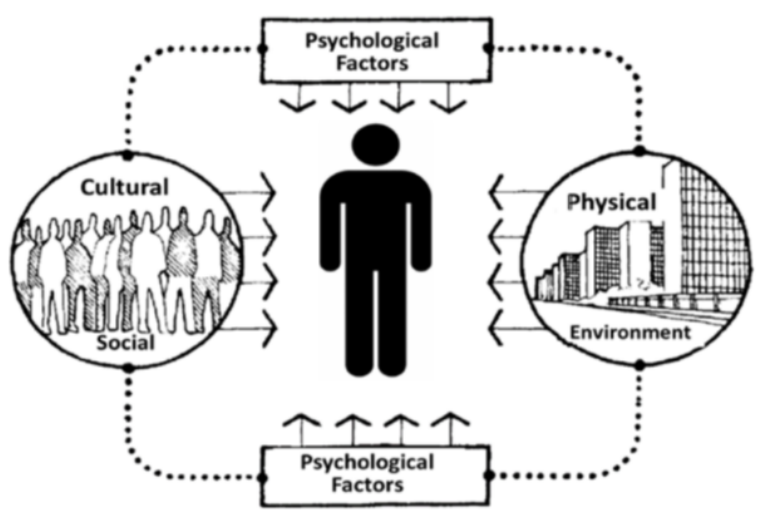

Figure 1. The factors that can influence the user's perception [3]

Groter [2] mentioned that the relationship between the interior and exterior provides an opportunity for movement, accessibility, and environmental connection. The researcher argued that location and form have a role in the creating the positive relationships between the interior and exterior or open space [2]. However, the interior space can be located between the exterior area and open area inside the buildings, which is the connection and the continuity point between the outdoor landscape and indoor landscape. There are various relationships between the interior and exterior or open space, which can provide visual, and environmental effects on the users of the interior space. Sedaghat, Khakpour, and Vahidi [4] explained that the relationship between outdoor and indoor can be in three types (Figure 2), which are; visual, audio, and availability. The researchers showed that there are different degrees of relationships. However, Sedaghat, Khakpour, and Vahidi [4] didn't mentioned the continuity relations which is related to the function type of the interior space. In the current study, continuity considered as a factor that can affects the users.

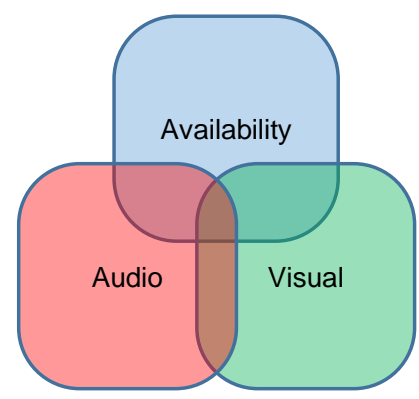

Figure 2. Relationships between surrounded \& open spaces [4]

Ünlü et al. [5] explained the relationships of interior and exterior settings and how it influences the users and educational environment in term of satisfaction. The architectural schools have a special design to match with the students' needs, which depends on the nature of architectural studio and galleries activities. The research compares between the users density in the ground floor spaces in sunny and rainy days. The comparative depends on three factors which are; functional attractiveness, milieu type, and location type using E-partition and Isovist analysis [5].

Watkins [6] identify seven strategies of sustainability in higher education buildings. The researcher mentioned that "defining sustainability needs philosophy, request green site, consider certifications, go not Zero, Compare techniques and materials, Calculate operating cost savings, and Involve your community are the main steps to produce a sustainable space" [6].

Watkins [6] explained that educational buildings should include a sustainable aspect, which can help to create a healthy environment. However, the relationship between interior and exterior design of the educational building can applied to achieve the comfortability. Omoregie et al. [7] evaluated the provision of sustainability in educational buildings through the use of CSIEB (Compressed Stabilized Interlocking Earth Blocks). The environmental, economic and social features are the main aspects. The researchers identified three types of sustainability as a following rate (See Figure 3); 34\% of social sustainability, $33 \%$ of economic sustainability and $33 \%$ environmental sustainability [7].

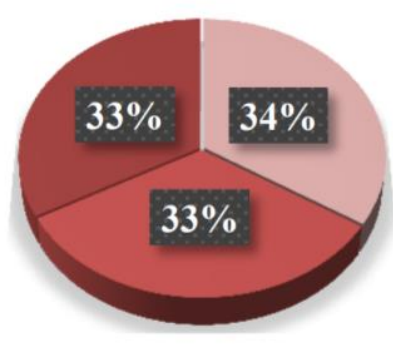

$$
\begin{aligned}
& \text { Social } \\
& \text { Sustainability } \\
& \text { Environmental } \\
& \text { Sustainability } \\
& \text { Economic } \\
& \text { Sustainability }
\end{aligned}
$$

Figure 3. The three types of sustainability in educational buildings [7]

Olson and Kellum [8] and Watkins [6] mentioned that sustainability in educational buildings reflected by the five main aspects. These aspects are; materials, thermal comfort, acoustic comfort, safety value, and out/Indoor connections. The researchers connected the sustainability values to the relationship between indoor and outdoor physical characteristics [6, 8]. Krstić et al. [9] find the relationships between the interior and exterior space in term of spatial layers of the buildings, which depends on the core, structure, and layout of the architectural buildings (Figure 4). The researchers explained the relationship as 'in Between' virtual place connected the interior to exterior and included characteristics from each side [9]. The natural lighting mentioned by researchers as a factor of healthy environment, which is part of the relationship between interior and exterior spaces [10].

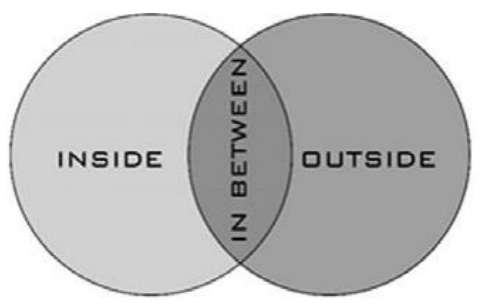

Figure 4. In between space [9] 
In summary, literature mentioned the important factors of the can be created by the value of the relationships between interior design (interior space) and exterior design (landscape, open spaces) that should be considered by the designers in the educational building, which divided to two groups; the first group aspects related to the psychological effects including (attached to place, comfortability, place like home, belonging to place) that influence the users' behaviour. The second group related to physical effects including (continuity, visual connection, building outline, orientation), which linked to the environment and sustainable factors. However, the current study designs a conceptual framework that depended on concluded aspects from the previous studies as shown in Figure 5. The current study focuses on the relationship between exterior and interior design in term of creating a sustainable place. Therefore, materials type, thermal comfort, thermal acoustic, and air circulation are considered the aspects of the study.

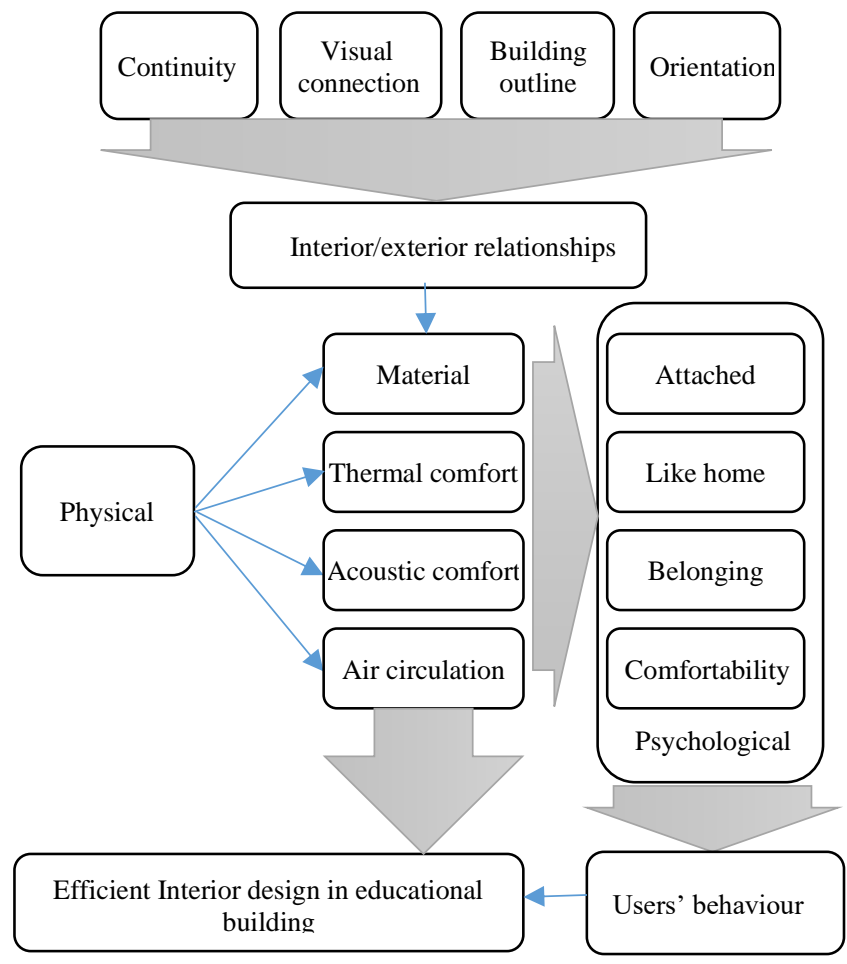

Figure 5. The conceptual framework of the study depending on the previous studies (Source: the researchers)

\section{RESEARCH DESIGN}

The current research is a quantitative approach, which used multi-quantitative methods and instruments to collect the data as following;

\subsection{Case study}

University of Mosul- College of Engineering - Architectural Engineering Department selected as a sample of a case study of university buildings in the main campus. The university located in the north state of Iraq (Nineveh Governorate) in Mosul City. The case study selection followed a special criterion conducted by observing the engineering departments buildings in the University of Mosul. The criteria of selecting included three indicators (Location, user type, and adaptive re- use building). The case study observed visually and notes taken about the physical environments after site visits. Observation for the students also conducted using taking sheet (place centre) to record activity and density and distribution of students in the space. Covered visual observation used to track the users of the students' area in the ground level of the architectural engineering department building. Where most of the activity running in this area. The visual observation used also to observe the building in term of visual steps, connection point with exterior, and continuity with exterior.

\subsection{Questionnaire techniques}

Questionnaire used to collect data from the users of the building (students), which used the interior and exterior space of the architectural school. The sample size is 189 represented the pubulation of the students, which are 244 undergraduate students and about 50 users from outside area mostly students from another departments or college. The users are verity in affiliation, which some not from the architectural engineering department. The questionnaire sheet designed as a structural survey, where included three themes. The first theme related to the thermal comfort, the second theme related to the psychological aspects, and the last theme related to the relationships between interior and exterior space. The collected data analysed statically. The questionnaire conducted during the day time between 10:00am and 02:00pm.

\subsection{Electronic instruments}

Simple electronic devices used to measure the thermal and acoustic value inside the building. The measuring conducted various points to cover all the area that linked to the outdoors. The measuring process applied during the day time (09:00 am to $02: 00 \mathrm{pm}$ ) for one week. The measuring conducted in middle of October, where the weather is moderate and, in the start, point of the academic year. This step of the methodology conducted to understand and match the thermal and noise influences on the users, with be triangulated with the result from the questionnaire.

\subsection{Triangulation of data from case study, questionnaire, and measurements}

This part is to connect the results from the three sources in order to highlight the effective factors and illustrate the responded of the users in team of thermal and psychological aspects. The triangulation used to validate the data that collected by various methods and sources.

\section{RESULTS AND DISCUSSION}

The architectural engineering department as a case study shows a sample of connecting and continuity between the indoor and outdoor area, which impacted the students' area and activate it to be used frequently by undergraduate, postgraduate, and staff. The layout of the ground floor provided a high quality of the connection between outdoor and indoor especially in the lobby, which the interior design of the buildings played master role in this connection. The students mentioned ( $63 \%$ of students) that the main door of the lobby and uncontrolled door affect the thermal comfortable value of the student area, especially in the windy, and rainy days, which 
is one of the effective factors mentioned by researchers [11]. This point explained the air circulation system of the building, which affect the students' comfortability. In the mediate and sunny days, the circulation system impacts the students positively. Also, students agreed that the air-conditioning system in the lobby area is enough but with controlling the doors.

For the same case, the air circulation and ventilation space are positively mentioned by $75 \%$ of students. Part of space impacted by the outdoor air circulations, which impacts the comfortable negatively during winter, while in spring, the case is different as the students' answers. $92 \%$ of samples recommended opening the double-door and windows to involve the area with comfortable air circulations and thermal value. The students were satisfied with the acoustic and noise value, except a few points in the area especially in the days that the place occupied for events such as gallery of academic events. $81 \%$ of students agreed that interior space should be free and open partially to the outdoor, in minimum visual connection. This point explained the students' view about the value of natural lighting, which $93 \%$ from the students were satisfied with the natural lighting in the lobby and surrounding area. The results of measurement of the sound, natural lighting, temperature, and humidity matched with the students' answers. Table 1 shows the measurement values of the thermal comfort factors, which show the normal values in the ground floor in the educational buildings.

The results of psychological aspect show the positive influence on the students' behaviour in the interior space of the Architectural Engineering Department building. The students act positively toward the place, which confirm the effects of physical and relationships between interior and exterior factors. The observation results matched with students' answers, which explained the important of the availability of the relationship between interior and exterior space. The attached to place factor observed clearly by the behaviour of students, which the lobby area are the point of meeting and activity. $78 \%$ from the students' answers that 90\%-95\% form their free time spent it in the ground floor and open area in front of the main door of the building. Figure 6 show the zones of most used area of the ground floor and exterior surrounding areas.

The lobby are the area where connected the path of students' movements inside and outside the building. Therefore, the students create a reference and magnet point in the place. The lobby and open area surround the building are the landed area of the student as show in Figure 6. The way of behaviours shows type of comfortability and adaptation in the place, which confirm the 'Belonging to place' and 'place like home' factors that show the successful interior design and its relationship with exterior space and open areas. The visual observation documented various type of students' activities, which is part of the positive behaviour toward the place. Figure 8 shows the word-cloud of the visual observation and tracking students in the interior space and exterior areas under the availability of connectivity and continuity factors. The activities were placed in the specific areas from the interior and exterior space, which Figure 7 show it.

The visual observation results of the case study (The Building of the Architectural Engineering Department) shows the availability of the relationships between the interior and exterior space, especially in the lobby area. The free space in the ground floor provided a strong visual connection with the outdoor area where are mostly green and open space area. Figure 9 show the five point that provided visual connection with outdoor area. Zone (A) is the strongest point in the case study and consequently (B), (C), (D), and (E) points.

Table 1. The average values of the thermal comfort elements in the interior space during 5 days

\begin{tabular}{ccccc}
\hline Days & Sound dB & Natural lighting Lux & Temperature- C & Humidity \% \\
\hline 1 & 55 & 45 & 23 & 13 \\
2 & 46 & 53 & 24 & 12 \\
3 & 56 & 51 & 21 & 9 \\
4 & 62 & 55 & 23 & 11 \\
5 & 53 & 49 & 21 & 13 \\
\hline
\end{tabular}

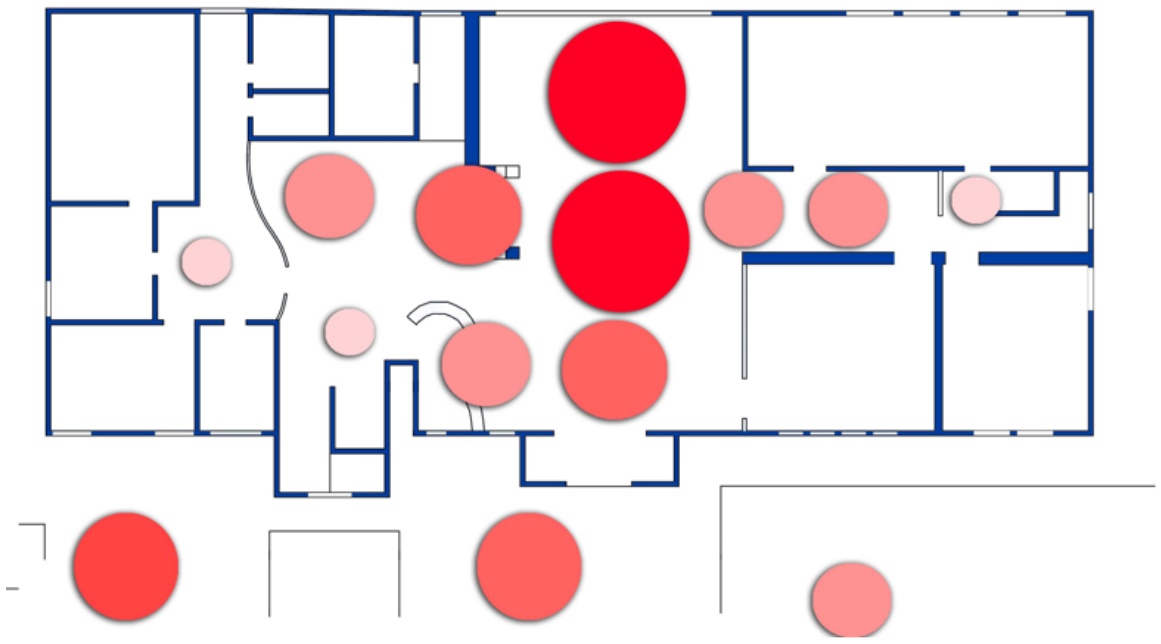

4-6 groups

90-120 mint.

2-3 groups

$60-90$ mint.

1-2 groups

$30-50$ mint.

$2-3$ students

$10-20$ mint

Figure 6. Disruption and spending time of students and groups in the ground and exterior surroundings area (Source: The researchers) 


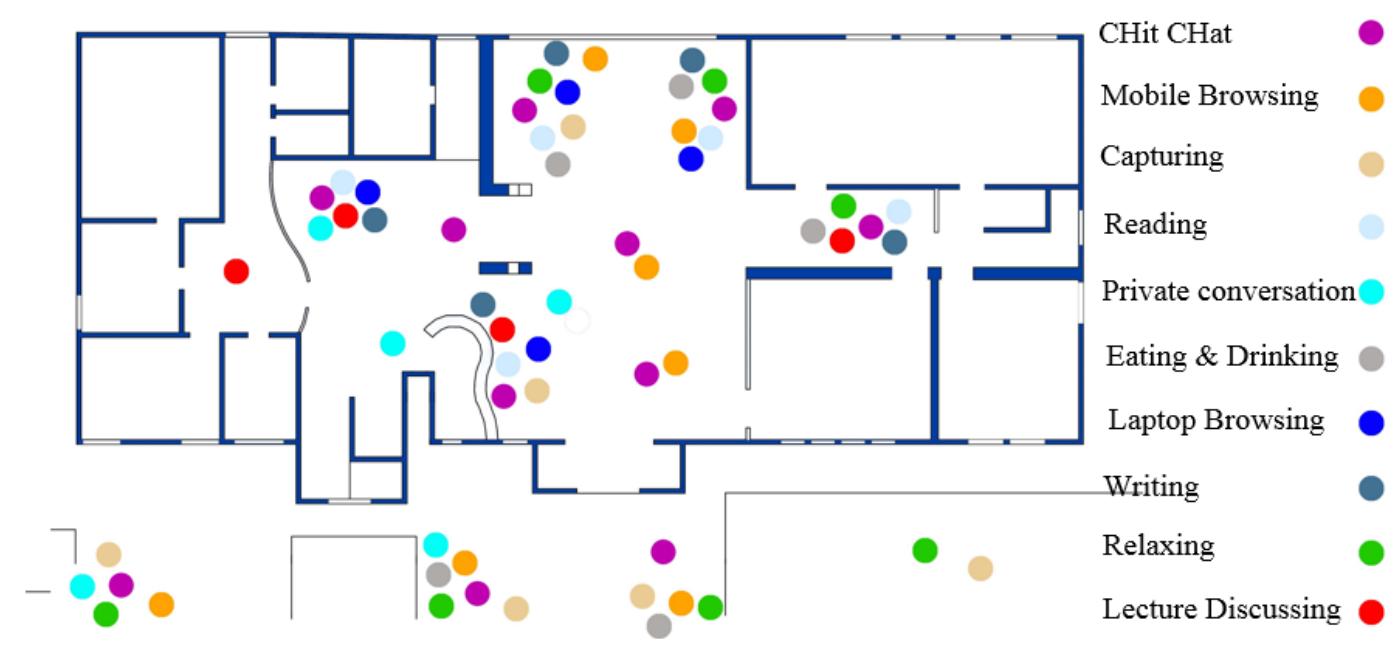

Figure 7. Tracking of activities in the interior and exterior area (Source: The researchers)

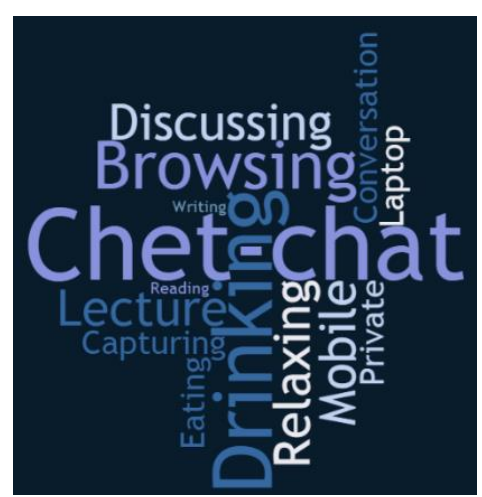

Figure 8. The results observation and tracking students in the place (source: The researchers)

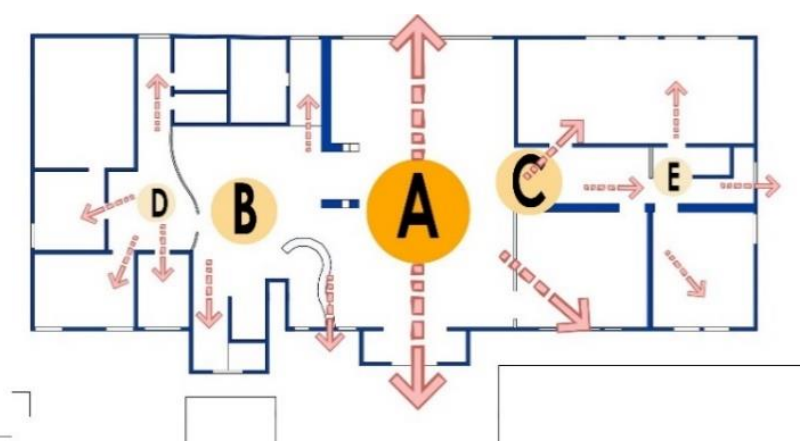

Figure 9. The visual connection areas with exterior and surrounding (Source: The researchers)

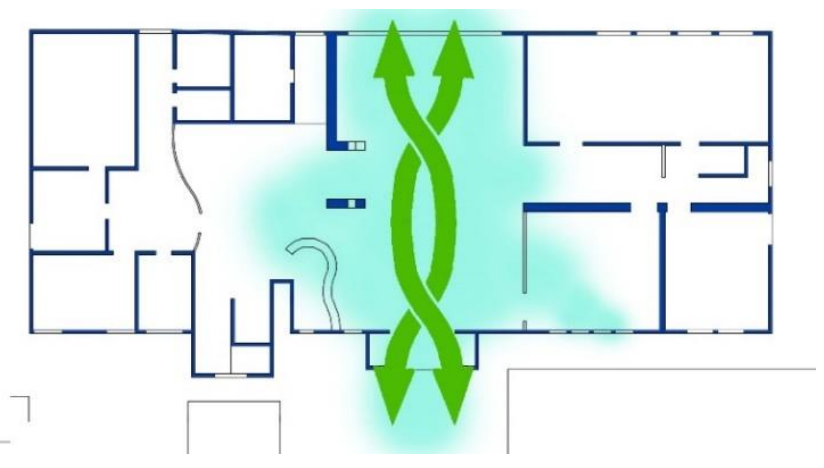

Figure 10. The continuity as a relationship factor in the case study (Source: The researchers)

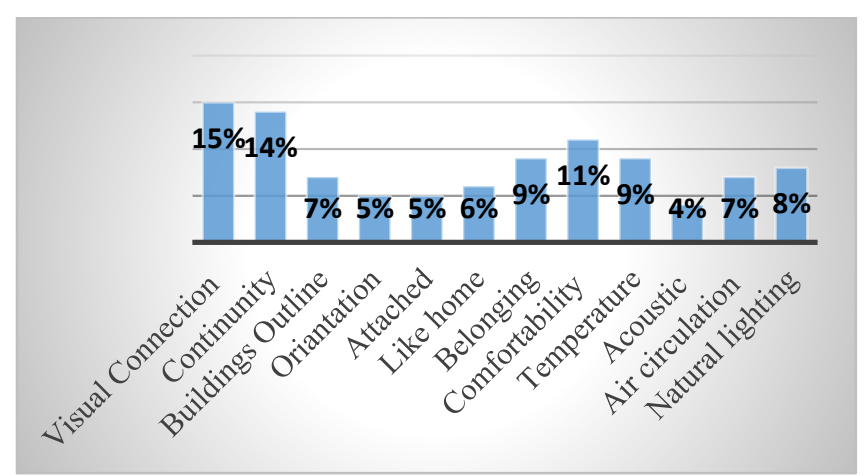

Figure 11. The main factors that can influence the students' behaviour and sustainability of the place in the interior design (Source: The researchers).

The continuity is clearly observed in the lobby area, which users were comfortable, satisfies, and adaption in the interior space. This shows the creative interior design characteristics, which should have considered in the design and adaptive reuse of the building in the University of Mosul (Figure 10).

The layout and orientation of the case study assist the activation of the relationships between the interior space and exterior or open spaces area. The characteristics of the building layout provided a type of environmental and educational sustainability in the buildings. The triangulation of the data from various resources by matching, overlapping, and intersection provided the final results that can represented as a guideline for interior design, adaptive re-use, or rehabilitation of the educational building in the University of Mosul. Figure 11 shows the influences factors on the students' comfortability and create a sustainable education environment in the building. These factors can be modified to be adapted for another building in the University of Mosul or any other places. These factors determined according the conceptual frame work that abstracted from the previous studies. The figure shows the triangulation of the data from observation of the case study and tracking the samples (students), Questionnaire, and results from measuring the physical environment inside the lobby and students' area.

\section{CONCLUSION}

The relationships between the interior and exterior space in 
the educational building have a role in the sustainability of the place in term of environmental and psychological effects on users' behaviour and function. The outcomes of the paper can be generalised for the educational buildings in Mosul City. The interior design of the educational buildings in the University of Mosul needs to re-formulate to reach the users' needs of comfortability, which influences the students' action toward their schools. The research illuminated the important factors of the relationship between interior and exterior space. The visual connection, continuity, and building design are the main factors that affect the physical and psychological situation of users' comfortability, which is in parallel affect the behaviour. Feeling 'place like home', belonging to place', attached to place', and comfortability are the reaction of the successful interior design of university buildings. It gives the motivation to the users to continue working and occupancy of the place. The interior design components, ventilation system, and controlling doors are parts of the relationships, which should have considered in the design, adaptive re-use, and rehabilitation processes in the University of Mosul. Attention to the psychological and physical comfort of college students should be a priority in the design process. Also, caring for green elements plays an important role in the liveability of the building.

\section{ACKNOWLEDGMENT}

The researchers acknowledge the Computer Engineering and Architectural Engineering Departments in Engineering College-university of Mosul, for registering the research under the scientific research plan 2019-2020, and for helping and allowing the researcher to collect data from students in the Architectural Engineering department building.

\section{REFERENCES}

[1] Mahmoud, H.H.T. (2017). Interior architectural elements that affect human psychology and behavior. International Journal on: The Academic Research Community Publication, 1(1): 1-10. http://dx.doi.org/10.21625/archive.v1i1.112

[2] Groter, Y. (2009). Cosmetology in Architecture, Transilated by: Pakzad, Jahanshah; Homayoun,
Abdolreza. Shahid Beheshti University Press. Tehran.

[3] Moore, G.T. (1979). Architecture and human behaviour: The place of environment-behaviour studies in architecture. Wisconsin Architect, 18-21.

[4] Sedaghat, A., Khakpour, M., Vahidi, T. (2015). Relationship between the outdoor and indoor landscape of primary schools in order to promote the children learning (Through a viewpoint to the architecture of traditional schools of Iran). Science Journal (CSJ), 36(4): 656-670.

[5] Ünlü, A., Edgü, E., Cimsit, F., Salgamcioglu, M.E., Garip, E., Mansouri, A. (2009). Interface of indoor and outdoor spaces in buildings: A syntactic comparison of architectural schools in Istanbul. Proceedings of 7th International Space Syntax Symposium, Stockholm.

[6] Watkins, B. (2018). 7 Strategies for Sustainability in Higher Educational Buildings. [Online]. Available: https://www.facilitiesnet.com/green/article/7-Strategiesfor-Sustainability-in-Higher-Educational-Buildings-17809, accessed 12 Aug. 2019.

[7] Omoregie, A.D., Alabi, A.O., Imuetinyan, A.E. (2016). Providing sustainability in educational buildings through the use of compressed stabilized interlocking earth blocks. Journal of Construction Engineering, Technology and Management, 6(2): 130-140.

[8] Olson, S.L., Kellum, S. (2003). The Impact of Sustainable Buildings on Educational Achievements in K-12 Schools, Wisconsin: Leonardo Academy Inc.

[9] Krstić, H., Trentin, A., Jovanović, G. (2016). Interiorexterior connection in architectural design based on the incorporation of spatial in between layers. Study of four architectural projects. SPATIUM, 1(36): 84-91. https://doi.org/10.2298/SPAT1636084K

[10] Younis, G.M., Abdulatif, F.S., Mostafa, W.S. (2019). Impact of design characteristics of daylight elements to creating healthy internal environment for school buildings evaluation the status of schools in Mosul city. Periodicals of Engineering and Natural Sciences, 7(3): 1354-1372. http://dx.doi.org/10.21533/pen.v7i3.756

[11] Al-Azawi, A.A.F. (2014). The impact of changing the entries' location on the spatial configuration features for the educational buildings in the university of Mosul. AlRafidain Engineering Journal, 22(3): 84-107. http://dx.doi.org/10.33899/rengj.2014.88204 